\title{
Precocious Puberty in A Patient with Unusual Infantile Alexander's Disease
}

Satoshi Matsuo, Akira Nishimura, Yoshihiro Takeuchi, Akiko Misawa, Zenro Kizaki, Fumio Inoue, Hiroshi Yoshioka, Akihiko Kinugasa and Tadashi Sawada

Department of Pediatrics, Kyoto Prefectural University of Medicine, Kyoto, Japan

Key words: puberty, dysmyelination, Alexander's disease

\section{Introduction}

Alexander's disease is a very rare neurodegenerative disease, characterized pathologically by the widespread accumulation of Rosenthal fibers (1). Recently, Rosenthal fibers were proved to represent accumulations of $\alpha \mathrm{B}$ crystallin in the astrocytes in Alexander's disease (2). Our patient, clinically diagnosed as having Alexander's disease, showed precocious puberty at the age of 9 months. His developmental delay and the dysmyelination on magnetic resonance imaging (MRI) improved after the onset of precocious puberty.

\section{Case Report}

A male infant was born at 36 weeks gestation to unrelated parents by Caesarian section due to the mother's toxemia. Apgar scores were normal. He weighed 2,864 grams (+0.8 SD), and the head circumference was $34.0 \mathrm{~cm}$ (+1.0 SD). Myoclonic movements were noted soon after the delivery. He was referred to our hospital in the neonatal period because of ele-

Correspondence: Dr. Satoshi Matsuo, Department of Pediatrics, Kyoto Prefectural University of Medicine, Kawaramachi Hirokoji Kamigyoku, Kyoto 602 Japan vated $17 \alpha$-hydroxyprogesterone (17OHP). Further examination, however, revealed 17OHP to be normal. In the first month, his head circumference had grown $6 \mathrm{~cm}$ (Fig. 1). Cranial CT showed symmetrical low attenuation in the white matter, which was more extensive in the frontal lobes. There were brain atrophy and moderate dilatation of the lateral ventricles. At 2 months of age, he was admitted to our hospital for further investigation. He weighed $4.25 \mathrm{~kg}(-2.4 \mathrm{SD})$ and the head circumference was $41.0 \mathrm{~cm}(+2.0 \mathrm{SD})$. His anterior fontanel (6 $\mathrm{cm} \times 6 \mathrm{~cm}$ ) was larger than average for his age. His muscle tonus was weak and retracted breathing was observed. No abnormal reflex or paresis was present. The results of routine hematological and chemical studies were all within normal limits. Urinary organic acid analysis showed no abnormal findings. Brain MRI showed dysmyelination in the white matter. On the basis of the CT and MRI findings, the diagnosis of Alexander's disease was considered. Investigation of the lysosomal enzymes revealed normal activities. Clonazepam administration was started at 2 months of age, and myoclonus was well controlled. At 9 months of age, he showed pubic hair (Tanner stage II). His penis (Tanner stage 

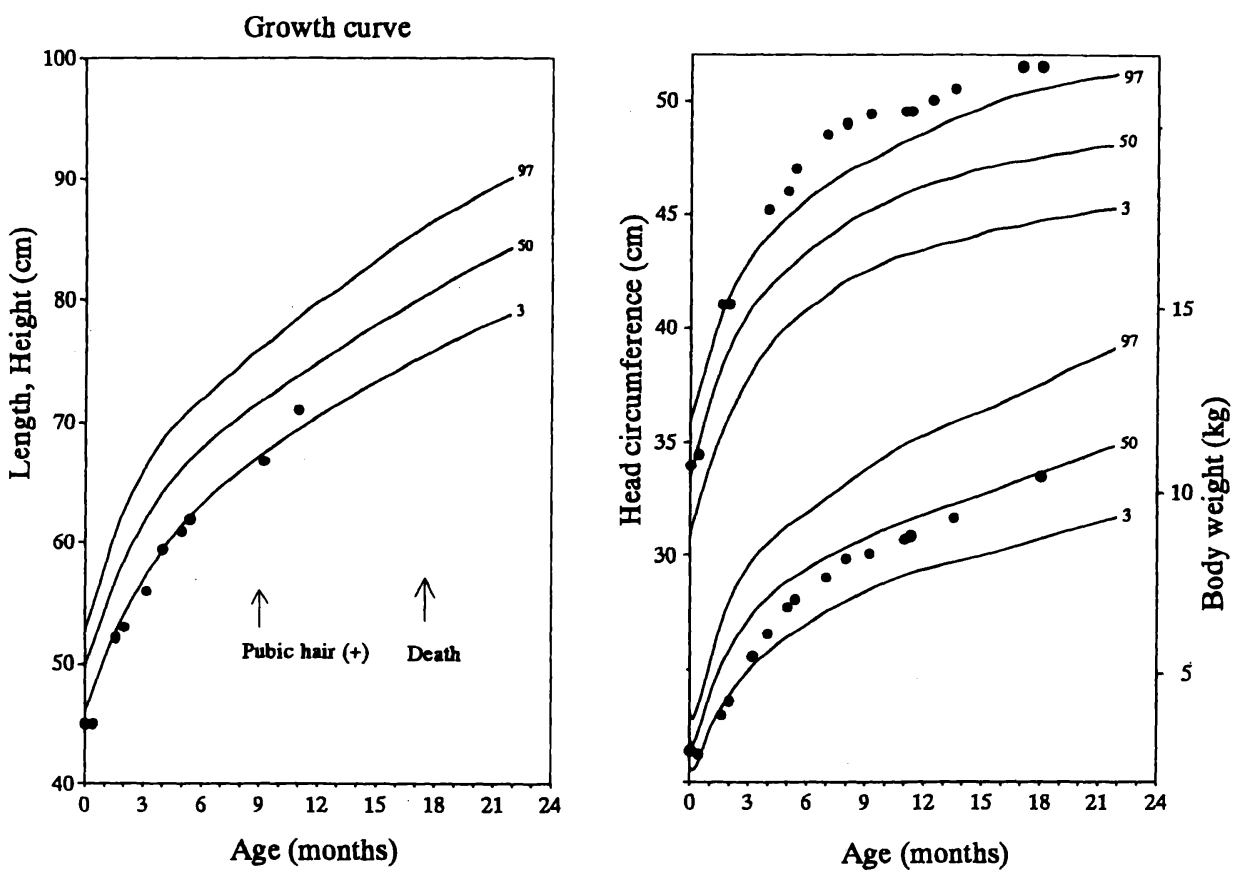

Fig. 1 Growth curve of the patient.

II) and testes (5 mL) had grown. Endocrinological examination revealed an elevation of testosterone $(3.0 \mathrm{ng} / \mathrm{mL})$ and the detection of HCG- $\beta$ subunit $(0.2 \mathrm{ng} / \mathrm{mL})$ (Table 1$)$. Loading of LH-RH resulted in a normal pattern. MRI revealed a small pituitary gland and no abnormal mass. The precocious puberty was thought to result from a brain lesion. On the other hand, his developmental delay and the dysmyelination on MRI improved after the onset

Table 1 Endocrinological data

\begin{tabular}{|c|c|}
\hline $170 \mathrm{HP}(\mathrm{ng} / \mathrm{mL})$ & 0.5 \\
\hline ACTH (pg/mL) & 53 \\
\hline Aldosterone $(\mathrm{ng} / \mathrm{mL})$ & 73.4 \\
\hline Cortisol $(\mu \mathrm{g} / \mathrm{dL})$ & 17.8 \\
\hline Testosterone $(\mathrm{ng} / \mathrm{mL})$ & 3.0 \\
\hline PRL (ng/mL) & 8.3 \\
\hline HCG-Bsubunit (ng/mL) & 0.2 \\
\hline DHEA $(\mathrm{ng} / \mathrm{mL})$ & 1.32 \\
\hline $\mathrm{u}-17 \mathrm{KS}(\mathrm{ng} / \mathrm{L})$ & 2.2 \\
\hline $\mathrm{u}-170 \mathrm{HCS}(\mathrm{ng} / \mathrm{L})$ & 9.2 \\
\hline
\end{tabular}

of precocious puberty. The patient died suddenly at 18 months after birth because of respiratory insufficiency. A post mortem examination was not permitted.

\section{Discussion}

We considered that the neurological improvements were induced by the change of his hormonal environment. The patient had shown a large head circumference and dysmyelination, which are usually present in Alexander's disease. Later, his brain caught up in myelination, which is not usual in Alexander's disease. Thus, we diagnosed him as having unusual infantile Alexander's disease.

Concerning the endocrinological aspects, the existence of precocious puberty suggests elevation of androgen. The elevation of testosterone supports this fact. In the central nervous system, androgen reverts to estrogen. 
Recently, Yuri et al.(3) reported that estrogen affects neuronal growth and synaptogenesis. In our patient it is likely that his hormonal environment such as elevated testosterone induced the myelination in his brain.

\section{References}

1. Pridmore CL, Baraitser M, Harding B, et al. Alexander's disease: Clues to diagnosis. J Child Neurol 1993; 8 (2): 134-44.

2. Iwaki T, Kume IA, Liem RK, et al. Alpha Bcrystallin is expressed in nonlenticular tissues and accumulates in Alexander's disease brain. Cell 1989; 57 (1): 71-8.

3. Yuri K, Kawata M. Time-course analysis of changes in calcitonin gene-related peptide- and methionine-enkephalin-immunoreactivity in the female rat preoptic area after estrogen treatment. Neuroscience 1993; 55 (4): 1067-74. 